\title{
Use of systematic reviews in clinical practice guidelines: case study of smoking cessation
}

\author{
C A Silagy, L F Stead, T Lancaster
}

\begin{abstract}
Objective To examine the extent to which recommendations in the national guidelines for the cessation of smoking are based on evidence from systematic reviews of controlled trials. Design Retrospective analysis of recommendations for the national guidelines for the cessation of smoking.

Materials National guidelines in clinical practice on smoking cessation published in English.

Main outcome measures The type of evidence (systematic review of controlled trials, individual trials, other studies, expert opinion) used to support each recommendation. We also assessed whether a Cochrane systematic review was available and could have been used in formulating the recommendation. Results Four national smoking cessation guidelines (from Canada, New Zealand, the United Kingdom, and the United States) covering 105 recommendations were identified. An explicit evidence base for $100 \%, 89 \%, 68 \%$, and $98 \%$ of recommendations, respectively, was detected, of which $60 \%, 56 \%, 59 \%$, and $47 \%$ were based on systematic reviews of controlled studies. Cochrane systematic reviews could have been used to develop between $39 \%$ and $73 \%$ of recommendations but were actually used in $0 \%$ to $36 \%$ of recommendations. The UK guidelines had the highest proportion of recommendations based on Cochrane systematic reviews.
\end{abstract}

Conclusions Use of systematic reviews in guidelines is a measure of the "payback" on investment in research synthesis. Systematic reviews commonly underpinned recommendations in guidelines on smoking cessation. The extent to which they were used varied by country and there was evidence of duplication of effort in some areas. Greater international collaboration in developing and maintaining an evidence base of systematic reviews can improve the efficiency of use of research resources.

\section{Introduction}

Good guidelines in clinical practice may help translate research findings into health gain. ${ }^{1}$ Guidelines should be based on a valid summary of the available evidence, and it has been shown that Dutch general practitioners were more likely to adopt recommendations that were evidence based than those that were not. ${ }^{2}$

Systematic reviews are an important source of valid evidence. ${ }^{3}$ However, undertaking and maintaining systematic reviews of high quality is resource intensive. The Cochrane Collaboration represents an international attempt to organise this type of activity across most fields of health care. ${ }^{4}$

Use of Cochrane reviews in guidelines for clinical practice is a possible measure of the "payback" on investment in the collaboration, but we do not know the extent to which they are used for this purpose Grant and colleagues evaluated payback on biomedical research based on papers cited in clinical guidelines. ${ }^{5}$ They found that only 3\% of cited references were systematic reviews. ${ }^{6}$ However, their approach does not necessarily reflect the extent to which systematic reviews were used to provide the evidence base for formulating specific recommendations within a guidelines document. ${ }^{7}$

We used smoking cessation as a case study to investigate the extent to which developers of national guidelines make use of systematic reviews. We also aimed to determine the source of systematic reviews used and the proportion of recommendations that could have been developed using an existing Cochrane review. We chose smoking because a large number of systematic reviews on this subject have been available for some time.

\section{Methods}

We searched the internet (using the free text terms "smoking cessation" and "guideline") and the US National Guidelines Clearinghouse (www.guideline. gov) to identify national guidelines on smoking cessation for clinical practice fully published in English

For each set of guidelines we identified the commissioning agency, the date that the guidelines were initially released, the date of the last search for evidence to be included in the guideline, the date of subsequent review of the guideline, the process for generating the guidelines, and individual recommendations. When there was more than one document associated with the guidelines, we focused on the recommendations contained in the document that targeted practitioners primarily.

We sought to identify the type of evidence used to support each recommendation, categorising evidence as systematic review, individual study(s), consensus of panel members, or not stated. We noted whether systematic reviews cited were Cochrane reviews, other published systematic reviews, or reviews undertaken as part of the development process for guidelines. When there was more than one document and the evidence supporting a recommendation was not identifiable in the primary document targeting practitioners, we examined other available documents.

For each recommendation we assessed whether a Cochrane review could have been used (at the time the guidelines were being prepared) to formulate the recommendation either directly or by extrapolation from the data in the review.

\section{Results}

We identified four national guidelines published in English without adaptation from an existing set of guidelines. ${ }^{9-12}$ Table 1 shows the country and commissioning agency for the four guidelines, together with

\section{Monash Institute of Health Services Research, Monash Medical Centre, Clayton, Victoria 3168, Australia C A Silagy professor and director Cochrane Tobacco Addiction Group, Imperial Cancer Research Fund General Practice Research Group Department of Primary Health Care, Institute of Health Sciences, Oxford OX3 7LF \\ L F Stead review group coordinator Department of Primary Health Care, Institute of Health Sciences T Lancaster reader \\ Correspondence to: C Silagy chris.silagy@med. monash.edu.au}

BMJ 2001;323:833-6 
Table 1 Description of guidelines included in case study of smoking cessation guidelines

\begin{tabular}{|c|c|c|c|c|}
\hline Country & $\begin{array}{l}\text { Agency with responsibility for developing } \\
\text { and issuing the guidelines }\end{array}$ & $\begin{array}{l}\text { Date guideline initially } \\
\text { released }\end{array}$ & $\begin{array}{l}\text { Date of last search for } \\
\text { included evidence }\end{array}$ & $\begin{array}{l}\text { Date for } \\
\text { review }\end{array}$ \\
\hline United Kingdom $^{10}$ & Health Education Authority (England) & December 1998 & September 1998 & Not stated $\dagger$ \\
\hline Canada $^{12}$ & Canadian Preventive Task Force & January 1994 (reviewed in 1998) & August 1993 (reviewed in 1998)‡ & Not stated \\
\hline
\end{tabular}

*The US guideline included articles identified for a previous version ${ }^{14}$ (which had been based on a search conducted for published articles between 1975 and 1994 ) as well as a more recent search for articles published between 1995 and 1999. It also contained some articles published after 1999 if they were known to the guideline panel and were deemed relevant. No final cut off date for the search was provided.

†The original guidelines did not state a date for review; an update was released in December $2000^{13}$ but was not available when the present study was completed. łAlthough the guidelines were reviewed in 1998 and were still considered current, there is no information about whether any additional searching was undertaken at that time.

the dates of release, last search for included evidence, and scheduled review (where recorded). The guidelines for the United States, United Kingdom, and New Zealand were all developed within the past two years. An updated amendment to the UK guidelines was released in late December 2000 (after this study was completed) and was, therefore, not included..$^{13}$ A review of the New Zealand guidelines was due in June 2001. The Canadian guidelines were developed in 1996 and reviewed during 1998, when the recommendations were still deemed relevant.

All four guidelines had clear documentation about the development process (table 2). In a number of cases this involved review and adaptation of existing material. Both the UK and New Zealand guidelines stated that they drew explicitly on Cochrane systematic reviews. All three non-US guidelines drew on reviews undertaken as part of an earlier US smoking cessation guideline. ${ }^{14}$ In addition, the guidelines for New Zealand explicitly drew on the UK guidelines. All assessed strength of evidence, although in the New Zealand guidelines this was provided in a separate document from the guideline document, which was targeted at practitioners. ${ }^{15}$

The number of clearly identifiable recommendations contained in the different guidelines varied from five (Canadian) to 60 (US) (table 3). Of these, we identified an explicit evidence base supporting the recommendations in most cases-that is, $68 \%, 89 \%$, $98 \%$, and $100 \%$-for the UK, New Zealand, US, and Canadian guidelines, respectively.

A Cochrane systematic review (that is, one that was available at the time of the last search undertaken in assembling the guidelines) could have been used, either directly or indirectly, to formulate 39\%-73\% of recommendations (table 4). Despite the potential to use Cochrane systematic reviews in this way, the proportion of recommendations specifically supported by a Cochrane review was much lower (0\%-36\%). The two North American guidelines in particular made little use of Cochrane reviews, with the US guidelines undertaking 26 new meta-analyses as part of the guideline development process. Of these, approximately two thirds covered topics similar to those covered by Cochrane systematic reviews. The UK and Canadian guidelines also relied heavily on published systematic reviews, particularly those from the earlier version of the US guidelines. ${ }^{14}$

\section{Discussion}

This study of smoking cessation shows that guideline developers provide detailed information about the steps involved in the development process. They were careful to ensure that most recommendations had an explicit evidence base. However, systematic reviews

Table 2 Development process for national guidelines in clinical practice

\begin{tabular}{|c|c|c|c|c|}
\hline Guideline & Commissioning agency & Method of guideline development & Identification of recommendations & Categorisation of evidence base \\
\hline United States & $\begin{array}{l}\text { Public Health Service US Department } \\
\text { of Health and Human Services }\end{array}$ & $\begin{array}{l}\text { Process described in document } \\
\text { Built on previous national guidelines } \\
\text { released in } 1996 \\
\text { Extensive literature review process of } \\
\text { original and meta-analytical articles } \\
\text { undertaken to update previous review } \\
\text { Reviewed by expert panel }\end{array}$ & $\begin{array}{l}56 \text { recommendations listed in bold print in } \\
\text { main text } \\
\text { Four additional recommendations identified } \\
\text { from text }\end{array}$ & $\begin{array}{l}\text { Recommendations categorised }(\mathrm{A}, \mathrm{B}, \text { or } \mathrm{C}) \\
\text { according to strength of evidence } \\
\text { Ratings attached to each recommendation; } \\
\text { references and results of meta-analyses } \\
\text { (where undertaken) provided within related } \\
\text { text }\end{array}$ \\
\hline New Zealand & $\begin{array}{l}\text { National Health Committee Ministry } \\
\text { of Health }\end{array}$ & $\begin{array}{l}\text { Process described in separate document } \\
\text { Reviewed previous US and UK guidelines } \\
\text { (including references) plus local New } \\
\text { Zealand review } \\
\text { No statement about additional literature } \\
\text { searching } \\
\text { Reviewed by expert panel }\end{array}$ & $\begin{array}{l}18 \text { recommendations in primary document } \\
\text { for practitioners highlighted in a bold box; } \\
\text { additional details provided for each in } \\
\text { another box } \\
\text { No additional recommendations identified }\end{array}$ & $\begin{array}{l}\text { No formal categorising of evidence } \\
\text { supporting recommendations in primary } \\
\text { document but evidence summary with } \\
\text { references provided } \\
\text { Separate summary of evidence and quality } \\
\text { of evidence reported in document on } \\
\text { literature review and background } \\
\text { information }\end{array}$ \\
\hline $\begin{array}{l}\text { United } \\
\text { Kingdom }\end{array}$ & Health Education Authority & $\begin{array}{l}\text { Process described in document } \\
\text { Based on expert panel review of systematic } \\
\text { reviews conducted by Cochrane Tobacco } \\
\text { Addiction Review Group and Agency for } \\
\text { Health Care Policy and Research (as part of } \\
\text { the former US guidelines) as well as the } \\
\text { American Psychiatric Association guideline }\end{array}$ & $\begin{array}{l}14 \text { numbered recommendations in main text } \\
\text { targeting health professionals (separate } \\
\text { recommendations targeting health } \\
\text { commissioners not included here) } \\
\text { No additional recommendations identified }\end{array}$ & $\begin{array}{l}\text { Recommendations categorised }(A, B \text {, or } C) \\
\text { according to strength of evidence } \\
\text { Ratings attached to each recommendation; } \\
\text { references provided within related text }\end{array}$ \\
\hline Canada & $\begin{array}{l}\text { Canadian Task Force on Preventive } \\
\text { Health Care }\end{array}$ & $\begin{array}{l}\text { Part of Canadian Task Force on Periodic } \\
\text { Health Examination } \\
\text { Process described in separate chapter within } \\
\text { document } \\
\text { Based on primary literature search with } \\
\text { review by expert panel }\end{array}$ & $\begin{array}{l}\text { Five recommendations presented in } \\
\text { summary table } \\
\text { No additional recommendations identified }\end{array}$ & $\begin{array}{l}\text { Recommendations categorised (A, B, or C) } \\
\text { according to strength of evidence } \\
\text { Ratings attached to each recommendation; } \\
\text { supporting references provided within an } \\
\text { adjacent column of summary table as well } \\
\text { as expanded in text }\end{array}$ \\
\hline
\end{tabular}


were used to support only about half of the total number of recommendations (and they supported a slightly higher percentage of those recommendations that mentioned an explicit evidence base). Of these, the proportion of recommendations based on a Cochrane review compared with a non-Cochrane systematic review varied depending on the country of origin of the guideline.

Generally, the North American guidelines drew on Cochrane reviews to a lesser extent than UK guidelines did. With the New Zealand guidelines the proportion of recommendations based on evidence from Cochrane systematic reviews varied depending on which of the two documents was considered. The document on literature review and background information makes extensive use of Cochrane reviews. ${ }^{15}$ The reason that the practitioner document makes less use of Cochrane reviews probably reflects the fact that several of the recommendations related to an area where there are currently no Cochrane reviews-for example, the establishment of systems of care (including prompting) to encourage practitioners to ask their patients about their smoking habits and to advise in a systematic way.

The reason for the relative lack of Cochrane reviews in the two guidelines developed in North America is unclear. One explanation could be the availability of Cochrane reviews in relation to the timing of developing the different guidelines. The initial release of the Canadian guidelines preceded the availability of any Cochrane reviews, but the review of these guidelines in 1998 could have drawn on a number of Cochrane reviews. Similarly, the US Agency for Health Care Policy and Research's 1996 smoking cessation guidelines (www.ahcpr.gov) were prepared before any Cochrane reviews were available. The US 2000 guidelines specifically mention consideration of other metaanalyses (and reference the entire Cochrane Library) in the description of methods. ${ }^{9}$ However, the evidence base draws mainly on updates of meta-analyses previously undertaken for the 1996 guidelines. This suggests that there is scope for improving international cooperation to reduce duplication of effort (and hence cost) in research synthesis.

Although the present study is based on a small sample, the guidelines mentioned have been widely adopted and used around the world by other national organisations. ${ }^{16}$ The extent to which the findings generalise to other topics is an area for further research.

We do not suggest that all clinical practice guidelines must use Cochrane systematic reviews as their primary source of evidence, or that Cochrane reviews are necessarily better quality than other systematic reviews. However, smoking cessation is an

Table 3 Use of systematic reviews to underpin recommendations in clinical practice guidelines. Values are numbers (percentages)

\begin{tabular}{lccc} 
& Total & $\begin{array}{c}\text { Recommendations } \\
\text { with explicit } \\
\text { evidence base }\end{array}$ & $\begin{array}{c}\text { Recommendations } \\
\text { based on } \\
\text { systematic } \\
\text { reviews }\end{array}$ \\
\hline United States & 60 & $59(98)$ & $28(47)$ \\
\hline New Zealand & 18 & $16(89)$ & $10(56)$ \\
\hline United Kingdom & 22 & $15(68)$ & $13(59)$ \\
\hline Canada & 5 & $5(100)$ & $3(60)$ \\
\hline
\end{tabular}

Table 4 Use of Cochrane systematic reviews in clinical practice guidelines. Values are numbers (percentages) of recommendations

\begin{tabular}{lccccc} 
& $\begin{array}{c}\text { Cochrane } \\
\text { systematic } \\
\text { review could } \\
\text { have been used }\end{array}$ & $\begin{array}{c}\text { Cochrane } \\
\text { systematic } \\
\text { review was } \\
\text { used }\end{array}$ & $\begin{array}{c}\text { Paper } \\
\text { publication of } \\
\text { non-Cochrane } \\
\text { systematic } \\
\text { review was used }\end{array}$ & $\begin{array}{c}\text { New systematic } \\
\text { review was } \\
\text { performed }\end{array}$ \\
\hline United States & 60 & $38(63)$ & $2(3)$ & 0 & $26(43)$ \\
\hline New Zealand & 18 & $7(39)$ & $2(11)$ & $8(44)$ & 0 \\
\hline United Kingdom & 22 & $16(73)$ & $8(36)$ & $5(23)$ & 0 \\
\hline Canada & 5 & $3(60)$ & 0 & $3(60)$ & 0 \\
\hline
\end{tabular}

${ }^{*}$ Figures presented here are based on the evidence base supporting recommendations identified in the document on primary guidelines. When the separate document on literature review and background information was reviewed, of 19 summary statements (that were not regarded as recommendations to practitioners), $13(68 \%)$ included reference to a Cochrane systematic review.

area in which a sizeable body of evidence is organised and updated systematically by the Cochrane Collaboration. In contrast with Grant et $\mathrm{al}^{56}$ we found, in the case of smoking cessation, that the recommendations of UK guidelines made extensive use of Cochrane systematic reviews. This is one source of evidence of the "payback" for the investment of funding organisations in supporting the systematic review process. ${ }^{17}$

Finally, we recognise that not all guideline recommendations can be underpinned by systematic reviews. Guideline developers can and should make recommendations that are specific to local contexts. However, reliable, up to date summaries of the evidence available internationally can allow guideline developers to reduce the costs associated with local guideline development.

Dr Mike Clarke and Dr Iain Chalmers provided helpful comments and feedback on drafts of the manuscript.

The Cochrane tobacco addiction review group is supported by the NHS Research and Development Programme and the Imperial Cancer Research Fund.

Contributors: CS and TL conceived the study and developed the protocol. CS identified the guidelines and initially extracted the data. LS checked the data. All authors contributed to writing the manuscript. CS is the guarantor for the paper. CS extracted and classified the data, resolving uncertainties by discussion with LS and TL.

Funding: None received for this specific project. TL and LS receive funds from the NHS research and development programme and the general practice research group of the Imperial Cancer Research Fund to support the infrastructure of the Cochrane tobacco addictions group.

Competing interests: CS and TL are editors of the Cochrane tobacco addiction group and LS is the review group coordinator of the same group. None of the authors stand to benefit directly or indirectly, financially, from increased use of the Cochrane Library. They have all been invited to provide comments and feedback on the US and UK guidelines as part of the process of the guidelines' development.

1 Woolf SH, Grol G, Hutchinson A, Eccles M, Grimshaw JG. Potentia benefits, limitations, and harms of clinical guidelines. BMJ 1999;318 $527-30$.

2 Grol R, Dalhuijsen J, Thomas S, Veld C, Rutten G, Mokkink H. Attributes of clinical guidelines that influence use of guidelines in general practice: an observational study. $B M J$ 1998;317:858-61.

3 Shekelle PG, Woolf SH, Eccles M, Grimshaw J. Developing guidelines. BMJ 1999;318:593-6.

4 Chalmers I, Dickerson K, Chalmers TC. Getting to grips with Archie Cochrane's agenda. BMJ 1992;340:786-8.

5 Grant J, Cottrell R, Cluzeau F, Fawcett G. Evaluating "payback" on biomedical research from papers cited in clinical guidelines: applied bibliometric study. BMJ 2000;320:1107-11.

6 Grant J, Cottrell R, Fawcett G, Cluzeau F. Evaluating "payback" on Grant J, Cottrell R, Fawcett G, Cluzea
biomedical research. BMJ 2000;321:566.

7 McDonald S. Systematic reviews cited in guidelines. [rapid response to (www.bmj.com/cgi/eletters/321/7260/566\#EL1)]. (accessed 5 Sep 2000)

8 Lancaster T, Silagy C, Sowden A, eds. Cochrane tobacco addiction module. In: Cochrane Collaboration. Cochrane Library. Issue 3. Oxford: Update Software, 2000. 
9 Fiore MC, Bailey WC, Cohen SJ, Dorfman SF, Goldstein HG, Gritz ER, et al. Treating tobacco use and dependence, clinical practice guideline. Rockville: US Department of Health and Human Services Public Health Service, 2000.

10 Raw M, McNeill A, West R. Smoking cessation guidelines for health professionals: a guide to effective smoking cessation interventions for the health care system. Thorax 1998;53(suppl 5):S1-19.

11 National Health Committee. Guidelines for smoking cessation. Wellington: Ministry of Health, 1999

12 Taylor MC, Dingle JL. Prevention of tobacco-caused disease. In: Canadian Task Force on the Periodic Health Examination. Ottawa: Health Canada, 1994:500-11.

13 West R, McNeill A, Raw M. Smoking cessation guidelines for health pro- fessionals: an update. Health Education Authority. Thorax 2000;55: 987-99

14 Fiore MC, Bailey WC, Cohen SJ, Dorfman SF, Goldstein HG, Gritz ER, et al. Smoking cessation. Rockville, MD: Agency for Health Care Policy and Research, 1996. (Clinical practice guideline no 18; US Department of Health and Human Services Publication no 96-0692.)

15 National Health Committee. Guidelines for smoking cessation: literature review and background information. Wellington: Ministry of Health, 1999.

16 Cohen D, Eliasson M, Ericksson C, Gilljam H, Hedin A, Hellenious M-L, et al. Smoking cessation methods. Stockholm: Swedish Council on Technology Assessment in Health Care, 1998.

17 Chalmers I. Evaluating "payback" on biomedical research. BMJ 2000;321:566.

(Accepted 14 May 2001)

\title{
Communication about sexual problems and sexual concerns in ovarian cancer: qualitative study
}

\author{
Maxine L Stead, Lesley Fallowfield, Julia M Brown, Peter Selby
}

Northern and

Yorkshire Clinical

Trials and Research

Unit, Leeds

LS2 9NG

Maxine L Stead

head of trial

coordination

Julia M Brown

head of unit (joint)

Cancer Research

Campaign

Psychosocial

Oncology Group,

School of Biological

Sciences, University

of Sussex, Brighton,

East Sussex

BN1 9QG

Lesley Fallowfield

professor of

psycho-oncology

Imperial Cancer

Research Fund

Cancer Medicine

Research Unit,

St James's

University Hospital,

Leeds LS9 7TF

Peter Selby

professor of cancer

medicine

Correspondence to:

M Stead

medmlst@leeds.

ac.uk

BMJ 2001;323:836-7
The assumption that ovarian cancer and its treatment (hysterectomy, oophorectomy, and chemotherapy) have considerable psychosexual effects is reasonable. Studies in other gynaecological cancers show that sexual activity is affected and that communication about this topic is poor. ${ }^{1-4}$ These issues have been neglected in ovarian cancer, so this qualitative study explored its psychosexual impact and the level of communication between women and healthcare professionals about sexual issues.

\section{Participants, methods, and results}

Detailed interviews were conducted with 15 women with ovarian cancer (median age 56 (range 42-71) years, median time since diagnosis 18 (8-120) months) who were identified from a sampling survey as sexually active or as inactive for reasons related to the condition. Topics included pre-diagnostic and current sexual behaviour and response, satisfaction with sex life, and importance of sex. Interviews were audiotaped, transcribed verbatim, and analysed using grounded theory methods, ${ }^{5}$ starting after the first interview. Each author read the transcript, noting themes and issues, and concepts pertaining to similar issues were grouped into categories. As more interviews were conducted, a thematic framework of the categories and their associated themes was produced, and this was systematically applied to each transcript, searching for evidence of the categories and themes. Semistructured interviews were conducted with the women and 43 clinicians and nurses in Leeds

Belief and reality regarding communication about sexual issues and concerns in patients with ovarian cancer

\section{Patients' beliefs}

Yes, medical staff should have talked to me about sexual issues:

- "it would help you understand that it is normal to feel like I did after the chemo and the operation"

- "I could have understood why I was having sexual problems if they'd have said 'you might have problems sexually because we've removed this or that"

- "it would have provided reassurance-light at the end of the tunnel"

- "you should know what's going to happen instead of it hitting you like a tonne of bricks"

\section{Patients' reality}

No, medical staff didn't talk to me about sexual issues:

- "I didn't know much about how sex would be affected, I just had to go through and find out for myself"

- "you have no idea about how the cancer will affect you sexually"

- "nobody talks about sex and you wonder whether it is right that you feel different"

- "the doctor said that if I was having problems with sex the hospital had creams to help me, but nothing else was said"

\section{Healthcare professionals' beliefs}

Yes, we should discuss sexual issues with patients:

- "which sexual problems may occur"

- "why sexual problems may occur"

- "reassurance that sexual activity will not cause a recurrence"

- "reassurance that sexual problems are normal"

- "advice or help is available"

\section{Healthcare professionals' reality}

No, we don't often discuss sexual issues with patients:

- "it's not my responsibility"

- "talking about sexual issues is too embarrassing"

- "I'm not sure what types of sexual problems patients experience"

- "I don't feel confident talking to patients about sexual issues"

- "there's nowhere to talk to patients in private"

- "there's no time to discuss sexual issues"

- "I wait until a patient asks about sex" 